\title{
Archeozoologické spracovanie zvieracích pozostatkov zo šibenice pri Slavkove
}

\author{
Lenka Jurkovičová \\ Ústav antropologie, Př́rodovědecká fakulta Masarykovy univerzity; Kotlářská 267/2, 61137 Brno
}

Do redakce doručeno 9. září 2017; k publikaci přijato 6. listopadu 2017

\section{ARCHAEOZOOLOGICAL ANALYSIS OF THE ANIMAL REMAINS FROM SLAVKOV GALLOWS}

\begin{abstract}
With the aim to broaden the context of the Slavkov gallows archaeological situation, an archaeozoological analysis was carried out in order to describe the occurrence of animal species at this site. Based on the detailed evaluation of the bones taphonomic characteristics, the analysed osteological material was divided into two historical periods. The first one belongs to the gallows original context, the second exhibits more recent character. Six species of domestic and wild fauna originate from the former archaeological era; several species of small mammals, as well as bird remains, have been identified in the second part of the collection. Evidence of human manipulations observed on domesticated fauna from the earlier period indicate the use of these animals as a part of the people's subsistence strategy at the execution site; traces of digestion by gastric acids and characteristic fractures on wild fauna bones during both eras refer to the possible accumulation of pellets by birds of prey at this site.
\end{abstract}

KEY WORDS archaeozoology; fauna; animal bones; butchering; subsistence strategies; gallows

\begin{abstract}
ABSTRAKT V doplnění kontextu informací o šibenici ze Slavkova byla provedena archeozoologická analýza, s cílem popsat výskyt živočichů na této lokalitě a rozširíit tak možnosti interpretace archeologické situace. Analyzovaný osteologický materiál byl na základě podrobného zhodnocení tafonomických projevů na kostech rozčleněn do dvou chronologických úseků - první náležející původnímu kontextu provozu šibenice, druhý spíše recentního charakteru. Z prvního období pochází šest druhů domácí i volně žijící fauny, v mladší části souboru bylo identifikováno několik druhů malých či drobných savců, a také pozůstatky ptactva. Lidské zásahy, které byly pozorovány na domestikované fauně ve starším období, svědčí o využití těchto zviŕat v rámci potravní strategie lidí na popravišti; stopy natrávení žaludečními štávami a charakteristické lomy na některých kostech volně žijící fauny v obou etapách odkazují na možné nahromadění vývržků dravým ptactvem.
\end{abstract}

KLÍČOVÁ SLOVA archeozoologie; fauna; zvířecí kosti; lidské zásahy; potravní strategie; popraviště

\section{ÚVOD}

Štúdium zvieracích pozostatkov vedie pri výskume historických populácií $\mathrm{k}$ bližšiemu poznaniu society a prehlbuje poznatky o človeku i životných podmienkach v spoločnosti. Analýzou je určená anatomická a taxonomická príslušnost' kostrových elementov, odhadnutý vek zvierata $\mathrm{v}$ dobe úmrtia, sú sledované prípadné patológie a tafonomické zmeny, $\mathrm{v}$ rámci ktorých sú $\mathrm{z}$ antropologického hladiska značne informačne prínosné stopy ludských zásahov zanechaných na kostiach v súvislosti s manipuláciou s telom zvie- rata (Binford 1981; Lyman 1994; Reitz, Wing 2008). V tejto štúdii je pozornost’ zameraná na zisk informácií o výskyte a úlohe zvierat pochovaných v objekte šibenice, čím môžeme sledovat jej históriu $\mathrm{z}$ pohladu vedúceho $\mathrm{k}$ prieniku do d’alšej úrovne poznania o prevádzke tohto exekučného zariadenia.

\section{MATERIÁL A METODIKA}

Archeozoologický súbor obsahuje celkom 128 (NISP = 128) kostí, zubov alebo ich fragmentov, ktoré boli na základe 


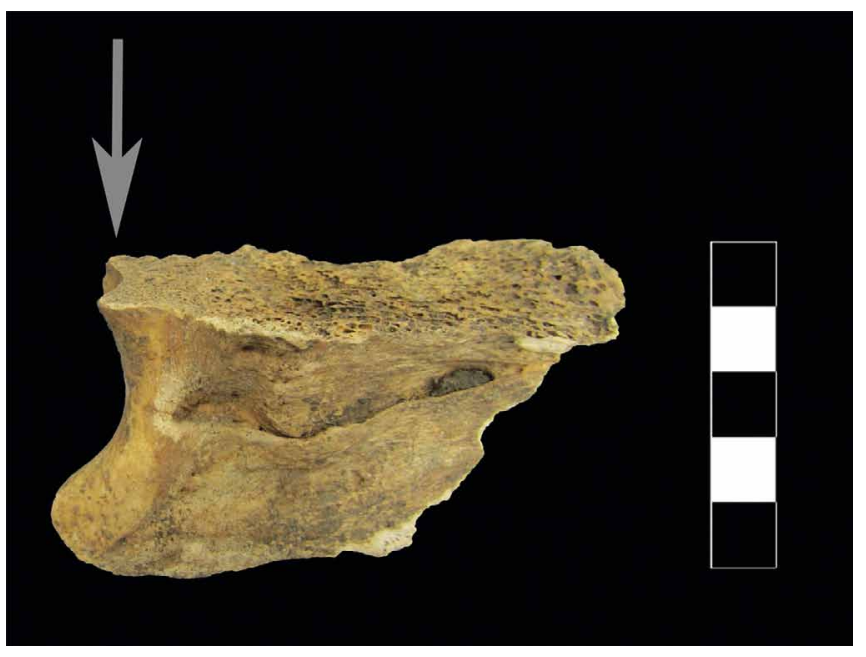

Obr. 1. Osekaná distálna čast’ kosti vretennej tura domáceho (Bos taurus).

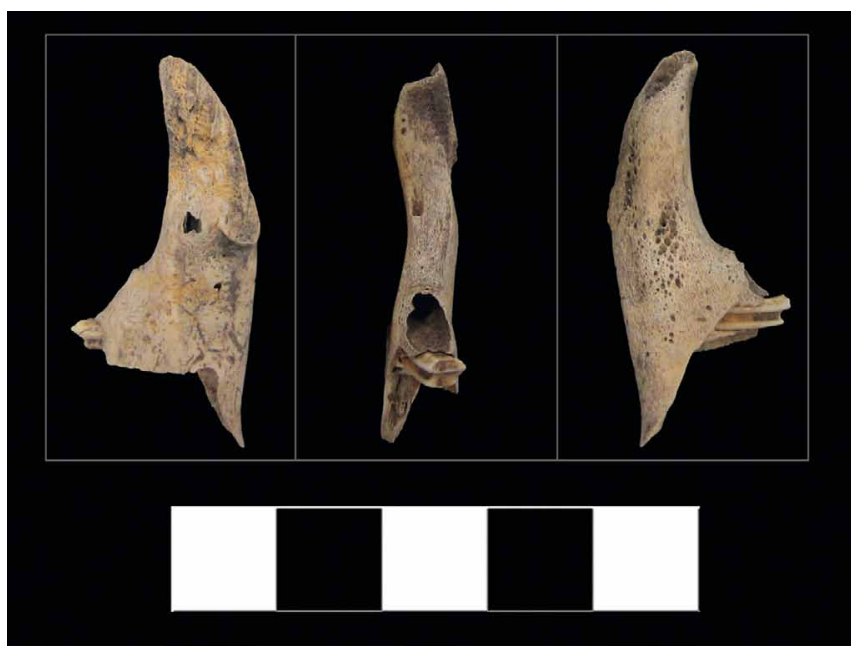

Obr. 3. Lavá spodná čelust’ zajaca polného (Lepus europaeus); linguálny, okluzálny, bukálny pohlad (zlava).

podrobného popisu stupňa a miery zachovalosti rozčlenené do dvoch chronologických úsekov - prvý je možné stotožnit s obdobím prevádzky šibenice (NISP = 64), druhý predstavuje nálezy skôr recentného charakteru (NISP $=64$ ). Vzhladom $\mathrm{k}$ tomu, že obe časti súboru vypovedajú o určitých tafonomických dispozíciách lokality, rozhodli sme sa ich analyzovat' súbežne, a to aj napriek tomu, že recentný materiál býva u archeozoologických analýz zvyčajne ponechaný stranou.

Materiál bol na základe znakov morfologicky špecifických pre daný druh anatomicky a taxonomicky určený (napr. Schmid 1972; Hilson 1992; Gentry et al. 2004; Hilson 2005; Franz 2008). Zástupcovia rodov ovca (Ovis) a koza (Capra) vykazujú $\mathrm{v}$ archeozoologických súboroch takmer zhodnú morfológiu kostí, preto ich označujeme jednou kategóriou ako ovcu/ kozu (Ovis/ Capra) (Reitz - Wing 2008). V prípade, že kvôli zlej zachovalosti či fragmentárnosti kostrových elementov nebolo možné určit konkrétny živočíšny druh, boli fragmenty zaradené do vel'kostných kategórií (velký cicavec

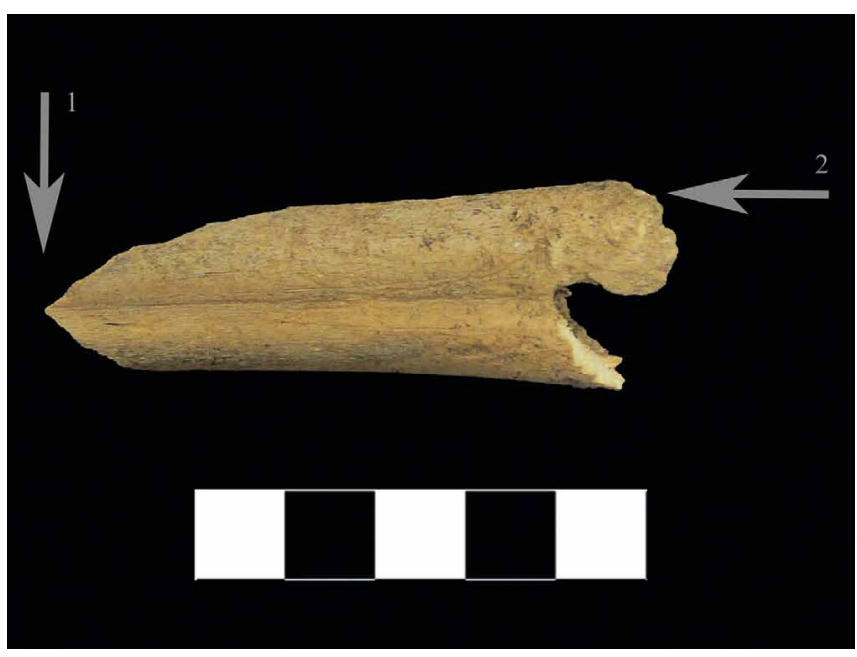

Obr. 2. Predpriehlavková kost’ ovce/ kozy (Ovis/ Capra), 1 - osekaná diafýza, 2 - ohryz mäsožravcom.

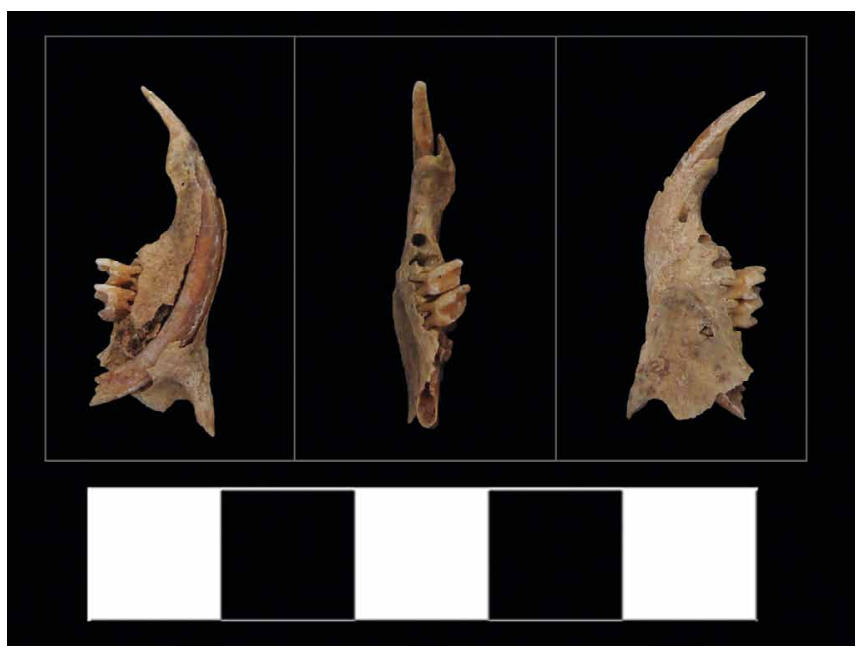

Obr. 4. Lavá spodná čelust' veverice obyčajnej (Sciurus vulgaris); linguálny, okluzálny, bukálny pohlad (zlava).

- vel'kosti tura/ jeleňa, stredne vel'ký cicavec - vel'kosti prasata/ srnca, malý cicavec - vel'kosti mačky/ zajaca, mikrofauna - napr. malé zemné hlodavce). Výsledky sú kvantifikované pomocou hodnoty NISP (number of identified specimens), vyjadrujúcej frekvenciu výskytu identifikovaných úlomkov priraditelných k taxónu alebo vel'kostnej kategórii; MNI (minimum number of individuals) bolo použité ako hodnota pre odhad najnižšieho možného počtu jedincov tvoriacich kostrový súbor (Lyman 1994; Grayson - Frey 2004). Na základe miery prirastania epifýz dlhých kostí a stupňa erupcie zubov bol pri analýze okrem taxonomického a anatomického určenia odhadovaný približný vek jedincov (Schmid 1972; Reitz - Wing 2008). Sledovaný bol v rámci tafonomického popisu kostí vplyv abiotických (napr. zvetranie, abrázia sedimentom, apod.) a biotických faktorov (napr. stopy po korienkoch rastlín, ohryz mäsožravcami či hlodavcami, natrávenie kostí žalúdočnými štavami, apod.). Medzi biotické činitele radíme tiež stopy ludských manipulácií s telami zvierat v podobe zá- 


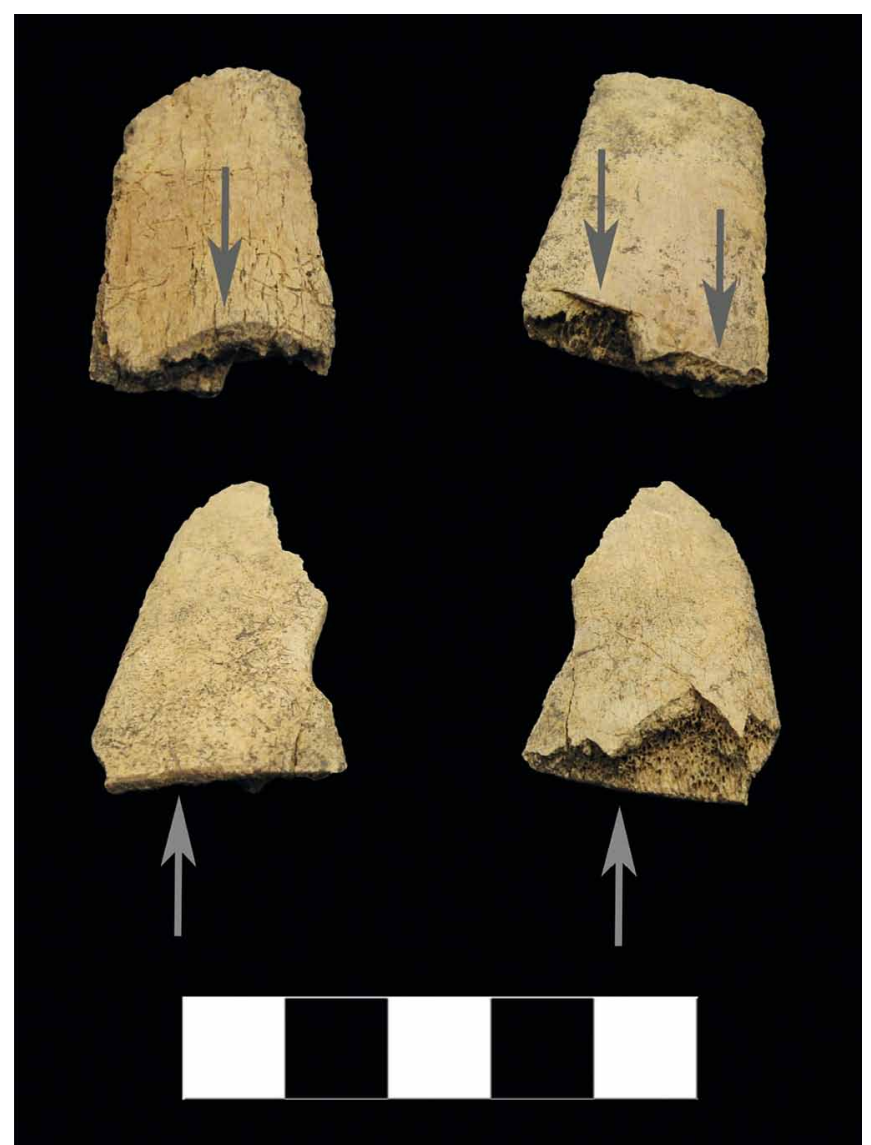

Obr. 5. Rebrá velkého cicavca s vyznačenými stopami ludských zásahov.

rezov, zásekov, drážok po škrabaní apod. (Binford 1981; Rixson 1989; Lyman 1994; Bochenski - Tornberg 2003; Reitz - Wing 2008; Pobiner 2008; Bochenski et al. 2009; Domínguez-Rodrigo et al. 2009; Armstrong 2016; Fernández-Jalvo et al. 2016; Sala - Arsuaga In Press).

\section{VÝSLEDKY}

Staršia čast’ súboru obsahuje tri druhy domestikovaných zvierat zastúpené ako dospelými, tak mladými jedincami - tur domáci (Bos taurus; NISP = 12; MNI = 1; osový skelet a kosti končatín; obr. 1), širšia skupina ovca/ koza (Ovis/ Capra; NISP =12; MNI = 1; zuby hornej čeluste, čast' spodnej čeluste so zubami, stavec, kosti oboch končatín; obr. 2) a sviňa domáca (Sus domesticus; NISP = 1; MNI = 1; fragment kosti laktovej). Medzi divoké druhy môžeme priradit' zajaca polného (Lepus europaeus; NISP $=11 ; \mathrm{MNI}=2$; lavá spodná čelust' a kosti oboch končatín; obr. 3) a vevericu obyčajnú (Sciurus vulgaris; $\mathrm{NISP}=6 ; \mathrm{MNI}=2$; lavá spodná čelust a kosti oboch končatín; obr. 4), a dalej taxonomicky bližšie neurčitelného vtáka malej velkosti (pravdepodobne spevavca) (Aves cf. Passeriformes; NISP $=1 ; \mathrm{MNI}=1$; behák). Z tafonomického hladiska bolo na pozostatkoch tura domáceho a širšej skupiny ovca/ koza

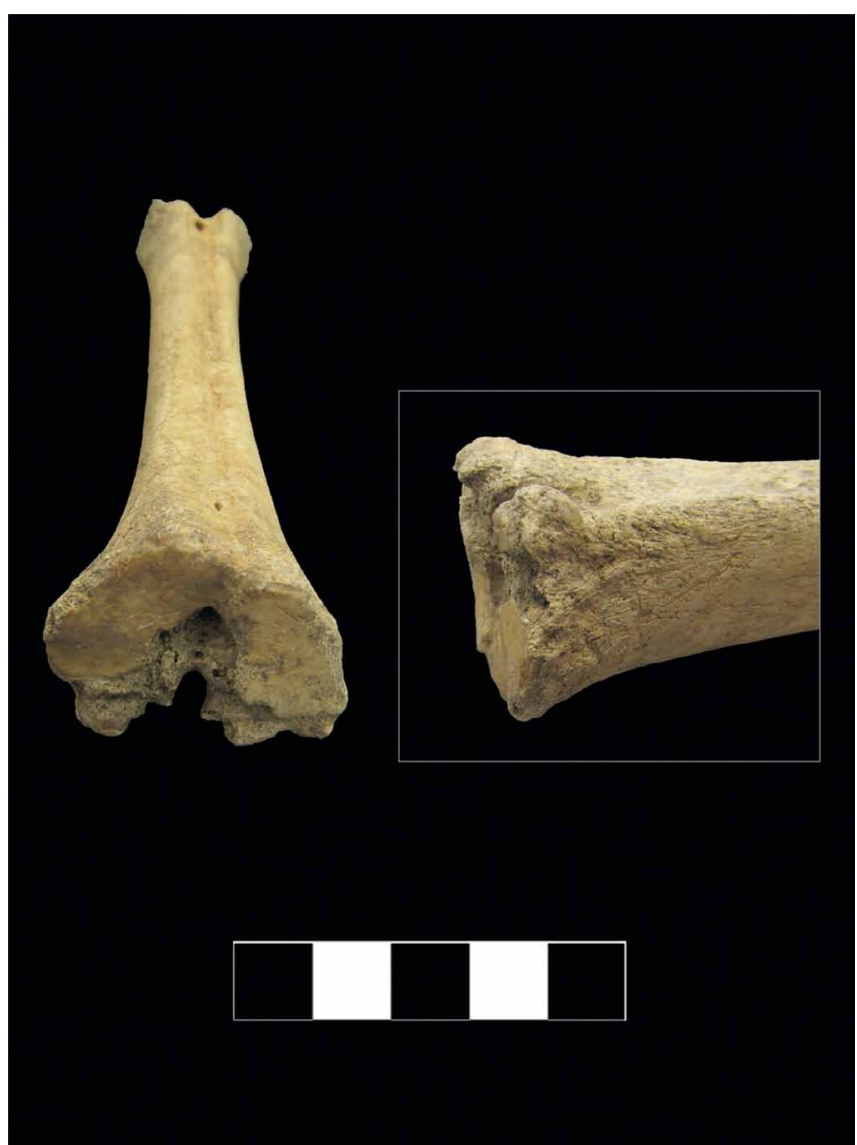

Obr. 6. Predpriehlavková kost’ tura domáceho (Bos taurus) s ohryzom mäsožravcom.

pozorované osekanie rebier, výbežkov stavcov a epifýz dlhých kostí (obr. 5; Binford 1981; Lyman 1994), prítomný je taktiež ohryz epifýz mäsožravcom (pravdepodobne psom alebo líškou; obr. 6; Pobiner 2008). Povrch niektorých kostí divokých druhov vykazuje stopy po natrávení žalúdočnými kyselinami i sériu charakteristických lomov, ktoré mohli vzniknút tlakom zobáka dravca (obr. 7; Bochenski - Tornberg 2003; Bochenski et al. 2009; Armstrong 2016; Fernández-Jalvo et al. 2016).

Mladšia čast’ súboru zahŕňa niekol'ko druhov malých a drobných cicavcov - zajac polný (Lepus europaeus; NISP = 21; MNI = 2; kosti oboch končatín; obr. 8), mačka domáca (Felis catus; NISP $=3 ; \mathrm{MNI}=1$; obe kosti pažné a pravá kost' stehenná; obr. 9), veverica obyčajná (Sciurus vulgaris; NISP = 3; MNI = 2; pravá kost' pažná a pravé kosti stehenné), škrečok (Cricetus sp.; NISP = 5; MNI = 2; kosti zadnej končatiny) a hlodavec vel'kosti potkana (Muridae cf. Rattus sp.; NISP = 9; $\mathrm{MNI}=3$; kosti oboch končatín), a d’alej kosti vtákov vel'kosti husi (Aves cf. Anseriformes; NISP = 8; MNI = 1; kosti osového skeletu a oboch končatín), jarabice (Aves cf. Galliformes; NISP = 10; $\mathrm{MNI}=1$; kosti osového skeletu a oboch končatín) a taxonomicky bližšie neurčitelného vtáka malej vel'kosti (NISP = 3; kosti osového skeletu a behák). Kosti končatín zajaca polného opät vykazovali stopy natrávenia a charakteristických lomov dravcom (obr. 10), i ked' ich s úplnostou nemôžeme vylúčit 


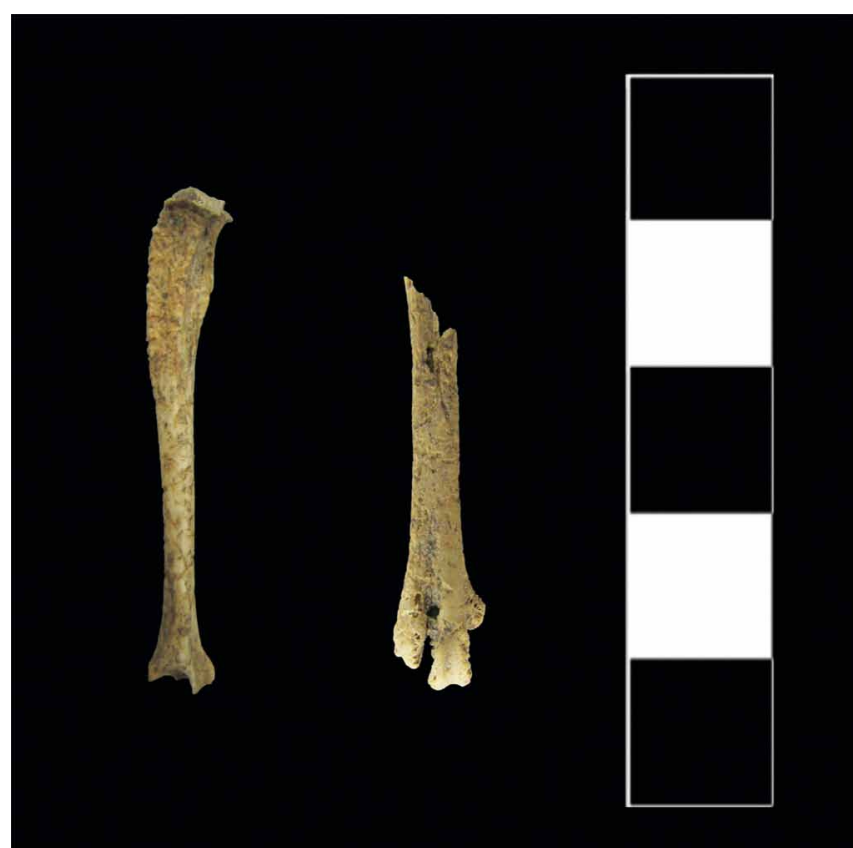

Obr. 7. Lavá kost’ holenná veverice obyčajnej (Sciurus vulgaris) a natrávený behák (Tarsometatarsus) malého vtáka (zlava).

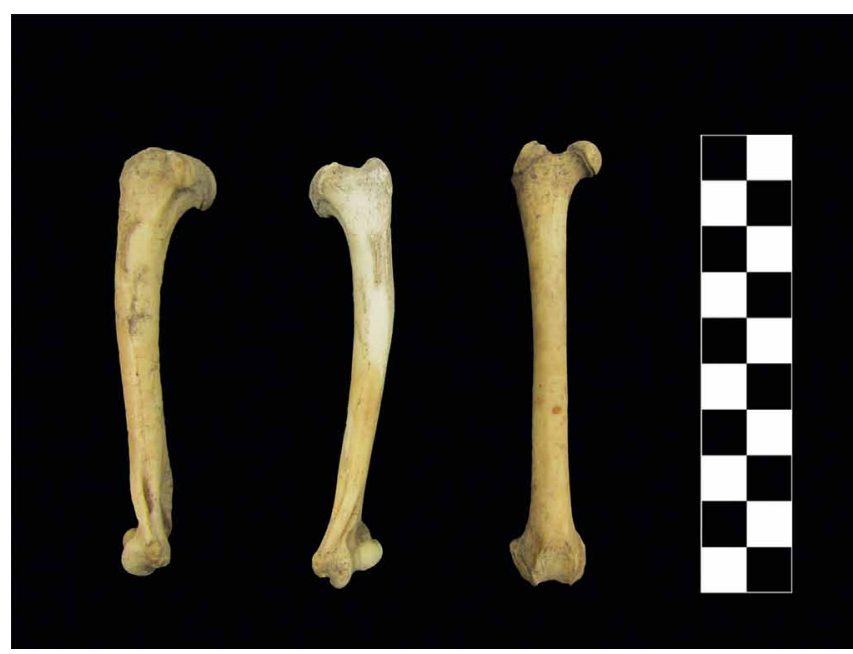

Obr. 9. Dlhé kosti končatín (lavá a pravá kost’ pažná; pravá kost’ stehenná) mačky domácej (Felis catus).

ani u drobných zemných cicavcov či vtákov (najmä v súvislosti s absenciou určitých skeletálnych častí; Bochenski - Tornberg 2003; Bochenski et al. 2009; Armstrong 2016; Fernández-Jalvo et al. 2016).

\section{DISKUSIA A ZÁVER}

Stopy ludskej manipulácie $\mathrm{v}$ podobe zásahov sledovaných na kostiach tura domáceho a ovce/ kozy zo staršej časti súboru nasvedčujú o pôvode týchto druhov na lokalite ako potravného odpadu. Pravdepodobne tvorili súčast jedálnička osôb zapojených do činností spojených s prevádzkou šibenice, alebo ludí

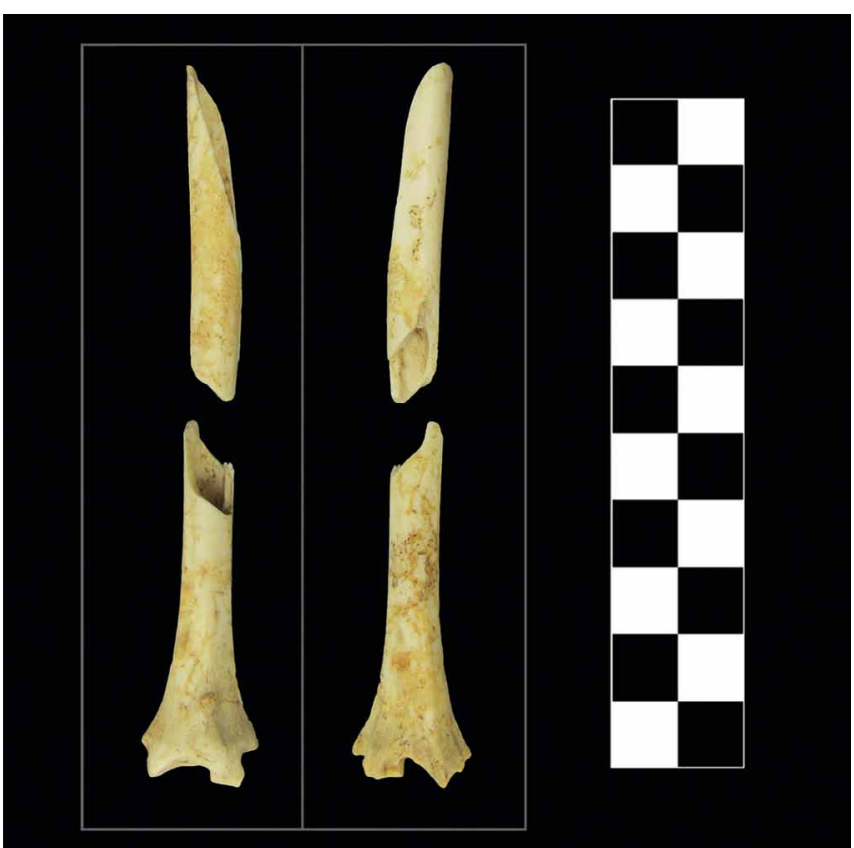

Obr. 8. Zlomená lavá kost' holenná zajaca pol’ného (Lepus europaeus); pohlad spredu a zozadu.

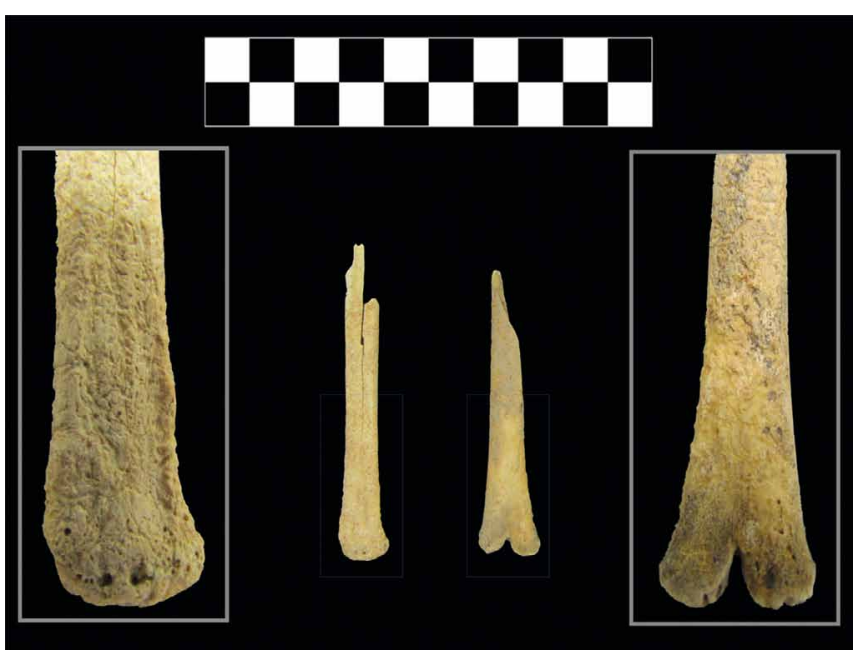

Obr. 10. Natrávené dlhé kosti končatín zajaca polného (Lepus europaeus).

prihliadajúcich poprave. Funkciu mrchoviska, podobne ako u šibeníc z Vodňan či Emmenbrücke (Manser - Diggelmann 1992; Kyselý 2006; Mašková - Michálek 2006) nepredpokladáme pre absenciu prepálenia, ktoré bolo na spomínaných lokalitách pre túto interpretáciu klúčovým indikátorom. Skladba druhového spektra aj d’alšie sprievodné stopy (fragmentarizácia, stopy po natrávení) by vzhladom $\mathrm{k}$ polohe a charakteru lokality - s prítomnostou vyvýšeného miesta (šibenice, $v$ mladšom období stromu alebo stĺpu vysokého napätia) - mohli svedčit o opakovanom nahromadení vývržkov dravého vtáka (porov. Bochenski - Tornberg 2003; Bochenski et al. 2009; Armstrong 2016). Niektoré hlodavce by tiež mohli na lokalite pôsobit' ako bioturbačné činitele (porov. Bocek 1986). 


\section{LITERATÚRA}

Armstrong, Aaron (2016): Eagles, owls, and coyotes (oh my!): Taphonomic Analysis of Rabbits and Guinea Pigs Fed to Captive Raptors and Coyotes. Journal of Archaeological Science: Reports 5, 135-155.

Binford, Lewis R. (1981): Bones: Ancient Men and Modern Myths. New York: Academic Press.

Bocek, Barbara (1986): Rodent Ecology and Burrowing Behavior: Predicted Effects on Archaeological Site Formation. American Antiquity 51, 589-603.

Bochenski, Zbigniew M. - Tornberg, Risto (2003): Fragmentation and Preservation of Bird Bones in Uneaten Food Remains of the Gyrfalcon Falco rusticolus. Journal of Archaeological Science 3 (12), 1665-1671.

Bochenski, Zbigniew M. - Tomek, Teresa - Tornberg, Risto - Wertz, Krzysztof (2009): Distinguishing Nonhuman Predation on Birds: Pattern of Damage Done by the White-tailed Eagle Haliaetus albicilla, with Comments on the Punctures Made by The Golden Eagle Aquila chrysaetos. Journal of Archaeological Science 36 (1), 122-129.

Dominguez-Rodrigo, Manuel - de Juana S. - Galan, Ana Belén - Rodriguez, María Rosa (2009): A new protocol to differentiate trampling marks from butchery cut marks. Journal of Archaeological Science 36, 2643-2654.

Fernández-Jalvo, Yolanda - Andrews, Peter - Denys, Christiane - Sesé, Carmen - Stoetzel, Emmanuelle - Marin-Monfort, Dolores - Pesquero, Dolores (2016): Taphonomy for Taxonomists: Implications of Predation in Small Mammal Studies. Quaternary Science Reviews 139, 138-157.

Franz, Diane L. (2008): Human and Nonhuman Bone Identification: A Color Atlas. Boca Raton: CRC Press.

Gentry, Anthea - Clutton-Brock, Juliet - Groves, Colin P. (2004): The Naming of Wild Animal Species and Their Domestic Derivatives. Journal of Archaeological Science 31, 645-651.
Grayson, Donald K. - Frey, Carol J. (2004): Measuring Skeletal Part Representation in Archaeological Faunas. Journal of Taphonomy 2 (1), 27-42.

Hillson, Simon (1992): Mammal bones and teeth: an introductory guide to methods of identification. Walnut Creek, Calif.: Left Coast Press.

Hillson, Simon (2005): Teeth. New York: Cambridge University Press.

Kyselý, René (2006): Zvířecí kosterní pozůstatky z popraviště ve Vodňanech. Archeologické rozhledy LVIII, 813-814.

Lyman, R. Lee, (1994): Vertebrate taphonomy. Cambridge Manuals in Archaeology. Cambridge: Cambridge University Press.

Manser, Jürg - Diggelmann, Kurt (1992): Richtstätte und Wasenpaltz in Emmenbrücke (16.-19. Jahrhundert): Archäologische und historische Untersuchungen zur Geschichte von Strafrechtspflege und Tierhaltung in Luzern I, II. Basel: Schweizerischer Burgenverein.

Mašková, Pavlína - Michálek, Jan (2006): Archeologický výzkum v poloze „Na šibenici“ ve Vodňanech (okres Strakonice). Př́íspěvek k archeologii popravišt v Čechách. Archeologické rozhledy 58, 790-809.

Pobiner, Briana (2008): Paleoecological Information in Predator Tooth Marks. Journal of Taphonomy 6 (3-4), 373-397.

Reitz, Elizabeth J. - Wing, Elizabeth S. (2008): Zooarchaeology. Cambridge Manuals in Archaeology. Cambridge: Cambridge University Press.

Rixson, Derrick (1989): Butchery Evidence on Animal Bones. Circaea 6 (1), 49-62.

Sala, Nohemi - Arsuaga, Juan Luis (In Press): Regarding Beasts and Humans: A review of Taphonomic Works With Living Carnivores. Quaternary International 2016, In Press.

Schmid, Elisabeth (1972): Atlas of Animal Bones. Amsterdam: Elsevier publishing company. 